\title{
EFFECTS OF ENDOCRINE AND INFLAMMATORY CHANGES ON MARKERS OF BONE TURNOVER FOLLOWING
}

\section{ROUX-EN-Y GASTRIC BYPASS SURGERY}

Tara S Rogers ${ }^{1}$, Peter J Havel ${ }^{2}$, Bruce M Wolfe ${ }^{3}$, Jeanne Blankenship, Michael M Swarbrick ${ }^{4}$, Kimber L Stanhope ${ }^{2}$, Mohamed R. Ali $^{6}$, Marta D Van Loan ${ }^{1,5}$

${ }^{1}$ Department of Nutrition

University of California, Davis

1 Shields Avenue

Davis, CA 95616

${ }^{2}$ Department of Molecular Biosciences, School of Veterinary Medicine

University of California, Davis

1 Shields Avenue

Davis, CA 95616

${ }^{3}$ Oregon Health and Sciences University

Department of Surgery

3181 S.W. Sam Jackson Park Rd.

Portland, Oregon 97239-3098

${ }^{4}$ Centre for Diabetes and Obesity

Westmead Millenium Institute

176 Hawkesbury Road

Westmead NSW 2145, Australia 
Effects of endocrine and inflammatory changes on markers of bone turnover following roux-en-y gastric bypass surgery

${ }^{5}$ USDA, ARS, Western Human Nutrition Research Center

430 West Health Sciences Drive

Davis, CA 95616

${ }^{6}$ Department of Surgery

University of California, Davis Medical Center

2315 Stockton Blvd

Sacramento, CA 95817

E-mail: marta.vanloan@ars.usda.gov

$\underline{\text { Abstract }}$

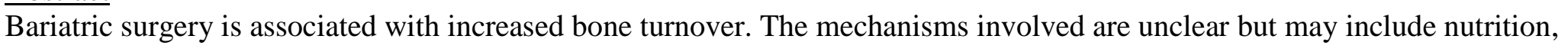

mechanical unloading, altered secretion of gastrointestinal and adipose hormones and changes in inflammatory status leading to

weight loss induced bone loss. We assessed markers of bone turnover in obese adults ( $\mathrm{F}=19, \mathrm{M}=1 ; \mathrm{BMI} 46.5+7.9 \mathrm{~kg} / \mathrm{m} 2)$ following

Roux-en-Y gastric bypass surgery (RYGB), and investigated their relationship to endocrine and inflammatory markers following this

procedure. Bone-specific alkaline phosphatases (BAP) and N-telo peptide of type I collagen (NTx) were measured as markers of bone

formation and resorption, respectively. Repeated measures analysis of variance (ANOVA) was used to evaluate differences over time.

Marta.vanloan@ars.usda.gov

Copyright 2015 KEI Journals. All Rights Reserved 
Effects of endocrine and inflammatory changes on markers of bone turnover following roux-en-y gastric bypass surgery

Step-wise multiple regression was used to model the contributions of body weight and composition, endocrine and inflammatory markers to bone metabolism (expressed as BAP/NTx). BAP/ NTx declined significantly $(\mathrm{p}<0.05)$ within one month after surgery and remained low for 12 months post RYGB. Before surgery, glucose (partial R2 $=0.23, \mathrm{p}=0.03$ ) and non-esterified fatty acids (FFA) (partial R2 $=0.12, \mathrm{p}=0.09$ ) explained $35 \%$ of the variance in BAP/NTx (model R2 $=0.35$ ). Twelve months after RYGB, $48 \%$ of variance in BAP/NTx was explained by glucose (partial $\mathrm{R} 2=0.21, \mathrm{p}=0.04$ ), insulin (partial $\mathrm{R} 2=0.17, \mathrm{p}=0.05$ ) and $\mathrm{C}$-reactive protein $(\mathrm{CRP})($ partial R2 $=0.10, \mathrm{p}=0.09$; model $\mathrm{R} 2=0.48)$ Changes in body weight and composition were not significantly related to the BAP/NTx ratio 12 months after surgery. In conclusion, the use of BAP/NTx ratio and stepwise regression models can be used to explore the inter-relationships between bone metabolism, endocrine and inflammatory markers over an extended period of persistent weight loss.

Key Words: bariatric surgery; Endocrine; hormones; inflammation; bone loss 
Effects of endocrine and inflammatory changes on markers of bone turnover following roux-en-y gastric bypass surgery

\subsection{Introduction}

Despite its efficacy in the treatment of morbid obesity, Rouxen-Y gastric bypass surgery (RYGB) has been reported to have deleterious effects on skeletal health. Cross-sectional and longitudinal studies have demonstrated increased bone turnover following this procedure [Coates et al. 2004, Bruno et al. 2010]. Decreased bone mineral density (BMD) at the lumbar spine, femoral neck and total femur one year after RYGB has been reported [Casagrande et al. 2012]; however, BMD of the hip may be impacted to a greater extent than spinal BMD [Yu 2014]. Though earlier work cast doubt on the clinical significance of such findings [Scibora et al. 2012], a recent historical cohort study of fracture incidence suggested a 2.3 fold increase in relative risk for any fracture after bariatric surgery. RYGB was the most common procedure in this study [Nakamura et al. 2014].

The American Association of Clinical Endocrinologists, The Obesity Society and the American Society for Metabolic and Bariatric Surgery released clinical practice guidelines in 2013 that addressed bone health after bariatric surgery. These recommendations include the measurement of BMD by dualenergy X-ray absorptiometry (DXA) at the hip and spine (or alternatively, the forearm) before surgery and two years after surgery for RYGB patients, as well as the promotion of

Marta.vanloan@ars.usda.gov

Copyright 2015 KEI Journals. All Rights Reserved 
Effects of endocrine and inflammatory changes on markers of bone turnover following roux-en-y gastric bypass surgery

adequate calcium and vitamin D intake [Mechanick et al. 2013, Stein and Silverberg 2014].

Proposed mechanisms for the effects of bariatric surgery on bone are multifactorial and involve nutrition, mechanical unloading and altered secretion of hormones from the gastrointestinal tract and adipose tissue [Folli et al. 2012]. Additionally, weight loss results in reductions of systemic markers of inflammation [Basu et al. 2006], which can in turn affect bone metabolism [McCormick 2007].

Calcium and vitamin D ingestion after RYGB may decline due to the expected reduction of food intake and variable compliance with supplementation regimens [Brzozowska et al. 2013, Stein and Silverberg 2014]. Circumvention of the duodenum and proximal jejunum reduces gastric acid production, and pre-existing vitamin $\mathrm{D}$ deficiencies inhibit calcium absorption [Brzozowska et al. 2013, Viegas et al. 2010, Folli et al. 2012]. Parathyroid hormone (PTH) levels rise to correct low serum calcium but this secondary hyperparathyroidism stimulates osteoclasts, resulting in increased bone resorption [Schweitzer 2007, Folli et al. 2012].

Gastric bypass surgery dramatically alters circulating endocrine factors produced by several organ systems. Anatomic rearrangement of the gastrointestinal tract reduces secretion of 
Effects of endocrine and inflammatory changes on markers of bone turnover following roux-en-y gastric bypass surgery

glucose-dependent insulinotropic polypeptide (GIP) and ghrelin and increases glucagon-like peptide-1 (GLP-1) and peptide tyrosine-tyrosine (PYY). Effects on serotonin are mixed. Hormones produced by the pancreas including insulin, proinsulin, glucagon and amylin also decrease [Swarbrick et al. 2008, Holdstock et al. 2003, Folli et al. 2012, Brzozowska et al. 2013, Hage and Fuleihan 2014]. Many of these endocrine changes are considered to have negative consequences on bone health.

Like the gastrointestinal tract, adipose tissue produces hormonal products; the most studied are leptin and adiponectin. Circulating leptin concentrations correspond with total body fat, thus reflecting energy stores, as well as recent energy balance and macronutrient intake [Havel 2004, Folli et al. 2012]. Leptin's primary role lies in feeding and body weight regulation via communication with the hypothalamus [GomezAmbrosi et al. 2008]. Obese individuals may be leptin resistant, despite high levels of this hormone [Frederich et al.1995, Considine et al. 1996]. Cell and animal studies have suggested contrasting roles of leptin on the bone, depending upon the route of administration [Cornish et al. 2002, Ducy et al. 2000, Turner et al. 2013]. Human studies typically pertain to endogenous leptin and have indicated positive [Yamauchi et al. 2001], negative [Blum et al. 2003], and no independent 
Effects of endocrine and inflammatory changes on markers of bone turnover following roux-en-y gastric bypass surgery

relationship [Koroglu et al. 2011, Jürmäe et al. 2009, Barbour et al. 2012] between leptin and bone health.

In contrast to leptin, circulating adiponectin concentrations are decreased in obese patients. Circulating levels of total and high molecular weight adiponectin increase as leptin decreases following RYGB [Swarbrick et al. 2006, Swarbrick et al. 2008]. Adiponectin stimulates receptor activator of Nuclear Factor Kappa-B Ligand (RANKL) and inhibits osteoprotegerin (OPG), although stimulation of osteoblasts and suppression of osteoclasts by adiponectin have also been reported [Viegas et al. 2010, Gomez-Ambrosi et al. 2008]. Complete roles of leptin and adiponectin on the human skeleton, particularly in the context of obesity, remain to be clarified.

Chronic systemic inflammation, often observed in obesity, stimulates RANKL, osteoclastogenesis, and bone resorption [McCormick 2007]. The pro-inflammatory cytokine C-reactive protein (CRP) has been shown to predict independently lumbar spine BMD in women with metabolic syndrome [Lee et al. 2011]. Changes in inflammatory markers following gastric bypass surgery have been reported [Swarbrick et al. 2008, Thomsen et al. 2013 and Riedl et al. 2008], but an exploration of the interactions between endocrine derived hormones and inflammatory markers on bone metabolism have been limited. 
Effects of endocrine and inflammatory changes on markers of bone turnover following roux-en-y gastric bypass surgery

$\underline{2.0 \text { Aim }}$

In this paper, we report a secondary analysis of the interrelationships among markers of bone turnover, gastrointestinal and adipose hormones and inflammatory markers following RYGB surgery. Elucidation of these relationships is relevant to the prevention and treatment of obesity, osteoporosis, and associated co-morbidities..

$\underline{\text { 3.0 Materials and Methods }}$

\subsection{Subjects:}

Twenty severely obese adults (19 females, 1 male; mean BMI $46.5+7.9 \mathrm{~kg} / \mathrm{m} 2$ ) were studied before Roux-en-Y gastric bypass surgery (RYGB) and 1, 3, 6, and 12 months postoperatively. Operations were performed at the University of California, Davis Medical Center or the Mercy San Juan Hospital in Sacramento, CA, USA. Fasting blood samples were collected at each time point. Body composition was assessed at baseline, 1, and 12 months after surgery. All subjects provided written informed consent and the Institutional Review Board of the University of California, Davis approved the experimental protocol.

3. 2 Anthropometric Measurements:

Marta.vanloan@ars.usda.gov

Copyright 2015 KEI Journals. All Rights Reserved 
Effects of endocrine and inflammatory changes on markers of bone turnover following roux-en-y gastric bypass surgery

Standard methods were used to measure height, weight, waist and hip circumferences. Height was measured using an Ayrton wall-mounted stadiometer (Model s100; Ayrton Corp. Prior Lake, MN) with patients standing erect and without shoes. Weight was measured on an electronic scale (Scaletronix, Scale Tronix, Inc. Wheaton, IL) without shoes, pockets empty and in minimal clothing. Waist and hip circumference were taken with a non-stretch tape measure. The waist was defined as the narrowest location between the last rib and the top of the iliac crest. Hip circumference was measured at the greatest breadth over the greater trochanter. Air-displacement plethysmography (BodPod, Life Measurements, Concord, CA,
USA) was used to assess body density with body composition (fat mass and lean mass) calculated from the Siri equation: \% fat $=((4.95 / \mathrm{Db})-4.50) * 100$ where $\mathrm{Db}$ is body density determined by BodPod. Systolic and diastolic blood pressures were measured using a Welch-Allyn automated blood instrument (Tycos 767 model, Beaverton, OR. the USA) and following a standard protocol of 2 minutes rest between measurements. If the first 2 readings differed by more than 10 $\mathrm{mm}$ a third measurement was taken.

3.3 Markers of Bone Metabolism: 
Effects of endocrine and inflammatory changes on markers of bone turnover following roux-en-y gastric bypass surgery

Serum bone specific alkaline phospatase (BAP; formation) and N-teleopeptide of type 1 collagen (NTx; resorption) were measured with enzyme linked immunosorbant assays (ELISA) (Quidel, San Diego, CA, USA and Wampole Laboratories, Princeton, NJ, USA, respectively).

\subsection{Additional Biochemical Measurements:}

As described previously [Swarbrick et al. 2008], radioimmunoassays (RIA) (Linco, St. Charles, MO, USA) were used to measure insulin and leptin. ELISA (R\&D Systems, Minneapolis, MN USA) was used to measure soluble intercellular adhesion molecule-1 (sICAM-1). A Quantikine high sensitivity (hs) ELISA (also R\&D Systems) was used to measure interleukin-6 (IL-6). An Immulite analyzer and hsCRP reagents (Diagnostic Products, Los Angeles, CA, USA) were used to measure C-reactive protein (CRP). ELISA (ALPCO Diagnostics, Salem, NH, USA) was used to measure total adiponectin. Ghrelin was measured by RIA (Phoenix Pharmaceuticals, Burlingame CA). Plasma glucose was measured with a YSI glucose analyzer (Yellow Springs, OH, USA). Concentrations of FFA were measured with an enzymatic assay (Waco Chemicals, Richmond, VA, USA). Visfatin was measured by ELISA (ALPCO Diagnostics, Salem, NH, USA). Cortisol was measured by RIA (DPC, Los 
Effects of endocrine and inflammatory changes on markers of bone turnover following roux-en-y gastric bypass surgery

Angeles CA). Blood lipids were measured with the Polychem Chemistry Analyzer (PolyMedCo, Inc., Cortlandt Manor, NY). Adropin was measured by ELISA (Peninsula Labortories, San Carlos CA). Osteopontin was also measured by ELISA (R\&D Systems, Minneapolis, MN, USA).

\subsection{Statistical Analysis:}

Continuous variables were assessed for normality using Shapiro-Wilkes and transformed as appropriate. Descriptive statistics was performed on baseline characteristics. Repeated measures analysis of variance (ANOVA) was used to evaluate differences over time. Since intermediate data were not available for sICAM-1, an unpaired t-test was used to evaluate differences between baseline and 12 months. Pearson correlation coefficients were used to explore relationships among biomarkers of bone turnover, endocrine hormones, and inflammatory markers at baseline and 12 months after surgery. Stepwise multiple regression analyses were used to model the contribution of body weight and composition, endocrine hormones and inflammatory markers to bone metabolism. SAS 9.2 was used for the regressions; GraphPad Prism was used for all other analyses.

$\underline{5.0 \text { Results }}$ 
Effects of endocrine and inflammatory changes on markers of bone turnover following roux-en-y gastric bypass surgery

Baseline characteristics of the twenty subjects prior to the surgery are presented in Table 1 . As expected in a population of severely obese individuals, mean values exceeded recommended levels for BMI, body fat, LDL cholesterol, triglycerides, and systolic and diastolic blood pressure.

Table 1. Baseline characteristics of subjects before Roux-en-Y gastric bypass (RYGB) surgery.

\begin{tabular}{|c|c|c|}
\hline Variable & Mean \pm Standard Deviation & Range \\
\hline Age (vears) & $40.7 \pm 7.8$ & $24.1-50.8$ \\
\hline BMI $\left(\mathrm{kg} / \mathrm{m}^{2}\right)^{*}$ & $46.5 \pm 7.9$ & $36.8-64.9$ \\
\hline Weight (kg) & $131.2 \pm 26.2$ & $99.5-221.6$ \\
\hline Body Fat $(\%)^{*}$ & $51.7 \pm 4.5$ & $37.6-59.4$ \\
\hline Total Cholesterol (mg/dl) & $177 . \overline{6} \pm 35.7$ & $107.0-238.0$ \\
\hline LDL Cholesterol (mg/dl)* & $103.7 \pm 32.8$ & $15.0-156.0$ \\
\hline HDL Cholesterol (mg/dl) & $41.8 \pm 10.0$ & $23.0-62.0$ \\
\hline Triglycerides (mg/dl)* & $161.5 \pm 120.8$ & $43.0-596.0$ \\
\hline $\begin{array}{l}\text { Systolic Blood Pressure } \\
(\mathrm{mmHg})^{*}\end{array}$ & $132.6 \pm 14.7$ & $111.0-161.9$ \\
\hline $\begin{array}{l}\text { Diastolic Blood Pressure } \\
(\mathrm{mmHg})^{*}\end{array}$ & $84.2 \pm 8.4$ & $67.0-106.0$ \\
\hline Glucose $(\mathrm{mg} / \mathrm{dl})$ & $99 \pm 19.9$ & $72.1-158.0$ \\
\hline Insulin (pmol/1) & $208.2 \pm 82.4$ & $93.8-350.7$ \\
\hline FFA (mmol/l) & $0.3 \pm 0.1$ & $0.03-0.52$ \\
\hline Cortisol ( $\mu \mathrm{g} / \mathrm{dl})$ & $8.5 \pm 3.6$ & $4.0-21.0$ \\
\hline Adropin (ng/ml) & $2.1 \pm 0.6$ & $1.3-3.5$ \\
\hline Visfatin $(\mathrm{ng} / \mathrm{ml})$ & $13 . \overline{6} \pm 5.0$ & $7.0-26.6$ \\
\hline Osteopontin (ng/ml) & $31.3 \pm 25.4$ & $4.1-81.4$ \\
\hline
\end{tabular}

Bone turnover results are shown in Figure 1. BAP significantly

decreased from baseline to 1 month post RYGB, then

Marta.vanloan@ars.usda.gov

Copyright 2015 KEl Journals. All Rights Reserved 
Effects of endocrine and inflammatory changes on markers of bone turnover following roux-en-y gastric bypass surgery

subsequently increased by 3 months post-surgery and remained elevated through the 12 month post-operative period. NTx progressively increased from baseline to 12 months post RYGB. The increase in resorption was significant as early as 3 months post-operatively (Figure 1B). Because both BAP and NTx demonstrated an overall increase over time, we used the BAP/NTx ratio as a means to express overall bone metabolism in the 12 months following RYGB. BAP/NTx declined significantly $(p<0.05)$ within one month of surgery and remained low for the 12 month period following RYGB (Figure 1C). The use of the BAP/NTx ratio demonstrated that the increase in BAP was not sufficient to match the increase in
NTx, resulting in a net loss of bone during the 12 months following RYGB.

Figure 1. Changes in fasting concentrations of (a) BAP, (b) NTx and (c) BAP/NTx ratio following RYGB.

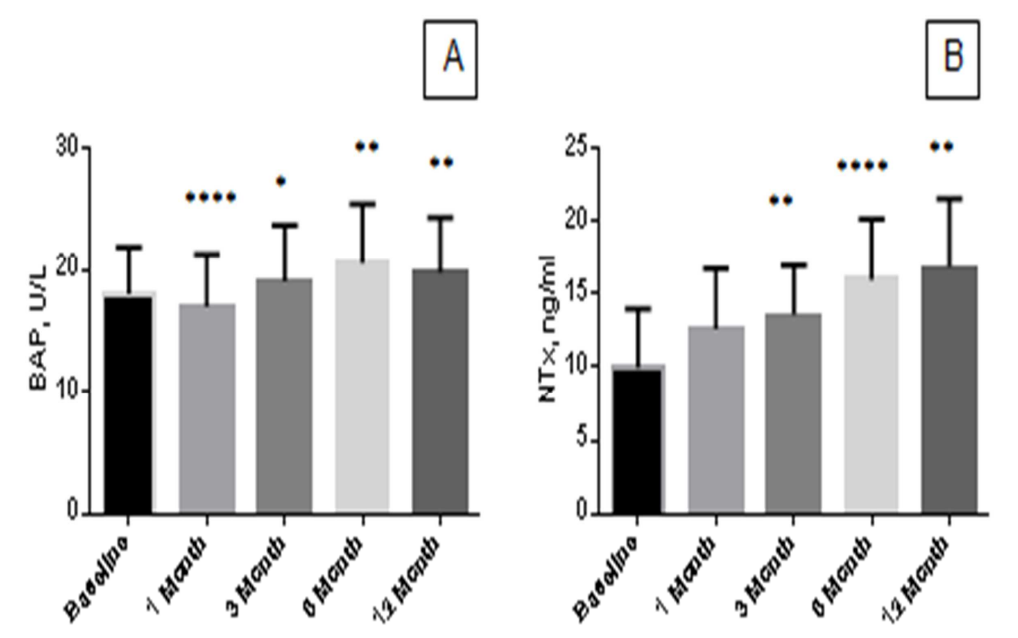


Effects of endocrine and inflammatory changes on markers of bone turnover following roux-en-y gastric bypass surgery

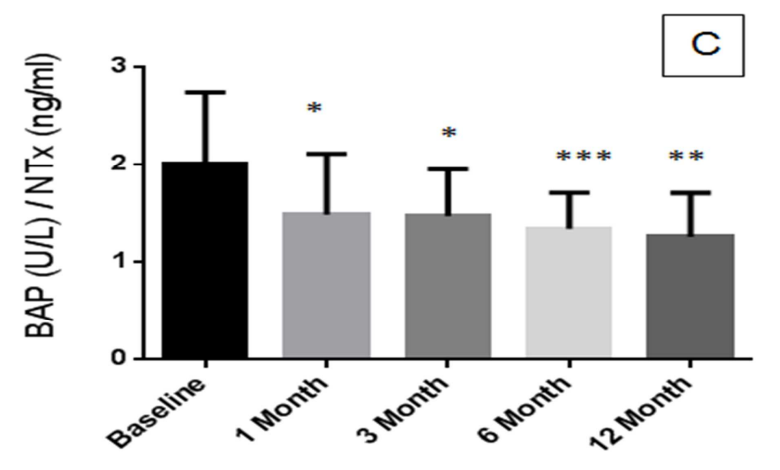

Significant differences from baseline are noted. $* \mathrm{p} \leq 0.05$, $* * \mathrm{p} \leq 0.01, * * * \mathrm{p} \leq 0.001, * * * * \mathrm{p} \leq 0.0001$.

Endocrine and inflammatory markers are presented in Tables

2A and 2B. The percent change in leptin was significant and declined throughout the post-operative period while the percent change in adiponectin was significantly increased during the 12 months post surgery. Insulin significantly and progressively declined from baseline starting as early as one month after surgery. Inflammation was evident by CRP and sICAM-1 values at baseline which decreased significantly with weight loss, demonstrating a reduction in the overall inflammation of the patients. IL- 6 data were only available for baseline, 1 and 12 months; although values declined they did not reach statistical significance.

Table 2A. Endocrine hormones before and after RYGB surgery. 
Effects of endocrine and inflammatory changes on markers of bone turnover following roux-en-y gastric bypass surgery

\begin{tabular}{|c|c|c|c|c|}
\hline Variable & l Month & 3 Months & 6 Months & 12 Months \\
\hline Leptin $(\% \Delta)$ & $-34.8 \pm 14.7^{3}$ & $-45.9 \pm 15.4^{6}$ & $-58.1+15.4^{\mathrm{dd}}$ & $-65.0 \pm 17.5^{\mathrm{d}}$ \\
\hline $\begin{array}{l}\text { Adiponectin } \\
(\% \Delta)\end{array}$ & $21.8 \pm 19.2^{\mathrm{a}}$ & $42.0 \pm 42.4^{3}$ & $54.6 \pm 54.1^{\mathrm{a}}$ & $79.6 \pm 65.6^{b}$ \\
\hline Insulin $(\% \Delta)$ & $\begin{array}{l}-87.0 \pm \\
90.7^{* * * *}\end{array}$ & $\begin{array}{l}-127.8 \pm \\
108.5^{* * * *}\end{array}$ & $\begin{array}{l}-156.7 \pm \\
101.8^{* * * *}\end{array}$ & $\begin{array}{l}-179.0 \pm \\
110 * * * *\end{array}$ \\
\hline Ghrelin $(\% \Delta)$ & $\begin{array}{l}-15.3 \pm \\
12.8^{* *}\end{array}$ & $-4.6 \pm 15.5$ & $-0.8 \pm 17.3$ & $8.3 \pm 14.6$ \\
\hline Glucose $(\% \Delta)$ & $-7.6 \pm 14.5$ & $-12.3 \pm 17.5$ & $-15.4 \pm 17.4$ & $-19.6 \pm 25.5$ \\
\hline
\end{tabular}

Table 2B. Inflammatory markers before and after RYGB surgery.

\begin{tabular}{llllll}
\hline Variable & Baseline & l Month & 3 Months & 6Months & 12Months \\
\hline CRP $(\mathrm{mg} / \mathrm{L})$ & $12.9 \pm 9.2$ & $9.1 \pm 6.1$ & $7.1 \pm 8.0^{*}$ & $5.1 \pm 6.0^{*}$ & $2.8 \pm 2.8$ \\
$\begin{array}{l}\text { sICAM-1 } \\
(\mathrm{mg} / \mathrm{ml})\end{array}$ & $248.0 \pm 45.9$ & -- & -- & -- & $217.9 \pm 39.7^{*}$ \\
$\amalg \mathrm{L}-6(\mathrm{pg} / \mathrm{ml})$ & $4.2 \pm 2.2$ & $3.9 \pm 1.5$ & -- & -- & $2.1 \pm 0.9$ \\
\hline
\end{tabular}

$\mathrm{N}=20 . \% \Delta=$ percent change from baseline. Analysis of variance (ANOVA); Values are means \pm standard deviations. Asterisks $(* \mathrm{p} \leq 0.05, * * \mathrm{p} \leq 0.01, * * * \mathrm{p} \leq 0.001, * * * * \mathrm{p} \leq 0.0001)$ denote significant differences from baseline. Superscripts denote significant differences between time points.
Pearson correlation coefficients were calculated to explore relationships among biomarkers of bone turnover, endocrine hormones, and inflammatory markers. Results for baseline and 12 months are presented in Table $\mathbf{3 A}$ and Table 3B, respectively. At baseline, significant relationships were found between NTx and body weight $(\mathrm{p}=0.003)$, fat mass $(\mathrm{p}=0.009)$ and sICAM-1 $(\mathrm{p}=0.03)$. The relationship between BAP and insulin at baseline approached significance $(\mathrm{p}=0.058)$. Twelve months after RYGB, no significant relationships were found between NTx and endocrine hormones or inflammatory markers. However, the association between BAP and insulin at 
Effects of endocrine and inflammatory changes on markers of bone turnover following roux-en-y gastric bypass surgery

the 12-month time point was significant $(\mathrm{r}=0.50, \mathrm{p}=0.02)$,

while the relationship between BAP and body weight

approached significance $(\mathrm{r}=0.43, \mathrm{p}=0.056)$. Significant

relationships between other variables are also noted.
Table 3A. Relationships among bone, endocrine, and inflammatory markers prior to RYGB

Marta.vanloan@ars.usda.gov

Copyright 2015 KEI Journals. All Rights Reserved 


\section{Medical Research Archives}

Effects of endocrine and inflammatory changes on markers of bone turnover following roux-en-y gastric bypass surgery

\begin{tabular}{|c|c|c|c|c|c|c|c|c|c|c|c|c|}
\hline & NTX & BAP & BAPINTX & Weight & Fat Mass & Insulin & Ghrelin & Leptin & Adiponectin & Osteopontin & SICAM-1 & CRP \\
\hline NTX & & 0.12 & $-0.77^{* \star \star \star}$ & $0.64^{\star \star}$ & $0.58^{\star \star}$ & 0.082 & -0.38 & 0.31 & -0.11 & 0.32 & $0.49^{*}$ & 0.11 \\
\hline BAP & 0.12 & & $0.47^{\star}$ & 0.22 & 0.16 & $0.44+$ & -0.37 & -0.007 & -0.31 & 0.24 & 0.39 & 0.003 \\
\hline BAPNTX & $-0.77^{* \star \star \star}$ & $0.47^{*}$ & & -0.44 & -0.39 & 0.24 & 0.17 & -0.28 & -0.11 & -0.10 & -0.07 & -0.19 \\
\hline Weight & $0.64^{\star \star \star \star}$ & 0.22 & -0.44 & & $0.90^{* \star * *}$ & 0.18 & $-0.55^{*}$ & 0.27 & -0.32 & 0.34 & $0.44+$ & 0.41 \\
\hline Fat Mass & $0.58^{\star \star \star}$ & 0.16 & -0.39 & $0.90^{\star \star \star \star \star}$ & & 0.17 & $-0.46^{*}$ & $0.54^{*}$ & -0.14 & 0.30 & 0.42 & $0.54^{*}$ \\
\hline Insulin & 0.08 & $0.44+$ & 0.24 & 0.18 & 0.17 & & -0.046 & 0.03 & -0.23 & 0.25 & 0.41 & 0.001 \\
\hline Ghrelin & -0.38 & \begin{tabular}{|l|}
-0.37 \\
\end{tabular} & 0.17 & $-0.56^{x}$ & -0.46 & -0.05 & & -0.13 & $0.47^{\star}$ & -0.23 & $-0.51^{x}$ & -0.43 \\
\hline Leptin & 0.31 & -0.007 & -0.28 & 0.27 & 0.54 & 0.03 & -0.13 & & -0.08 & -0.37 & 0.12 & $0.52^{*}$ \\
\hline Adiponectin & -0.11 & \begin{tabular}{|l|}
-0.31 \\
\end{tabular} & -0.11 & -0.32 & -0.14 & -0.23 & $0.47^{*}$ & -0.08 & & 0.11 & -0.41 & -0.14 \\
\hline Osteopontin & 0.32 & \begin{tabular}{|l|}
0.24 \\
\end{tabular} & -0.10 & 0.34 & 0.30 & 0.25 & -0.23 & -0.37 & 0.11 & & 0.44 & 0.13 \\
\hline SICAM-1 & $0.49^{*}$ & 0.39 & -0.07 & $0.44+$ & 0.42 & 0.41 & $-0.51^{*}$ & 0.12 & -0.41 & 0.44 & & -0.07 \\
\hline CRP & 0.11 & 0.003 & -0.19 & 0.41 & $0.54^{*}$ & 0.001 & -0.43 & $0.52^{*}$ & -0.14 & 0.13 & -0.07 & \\
\hline
\end{tabular}

Marta.vanloan@ars.usda.gov

Copyright 2015 KEI Journals. All Rights Reserved 
Effects of endocrine and inflammatory changes on markers of bone turnover following roux-en-y gastric bypass surgery

\begin{tabular}{|c|c|c|c|c|c|c|c|c|c|c|c|}
\hline 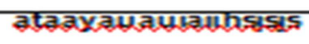 & $N \mid x$ & BAP & BAPINIX & Weight & Fatmass & Insulin & Ghreen & Amylin & Leptin & Usteoponten & Corbsol \\
\hline NIX & & 0.17 & $-0.73 \times * x$ & 0.08 & 0.06 & -0.05 & -0.18 & -0.11 & -0.03 & -0.38 & 0.07 \\
\hline BAP & 0.17 & & $0.53^{*}$ & $0.43^{*}$ & 0.38 & $0.50^{*}$ & -0.12 & -0.20 & 0.31 & -0.26 & -0.16 \\
\hline BAPINIX & -0.73 क्ष & $0.53^{*}$ & & 0.24 & 0.20 & 0.36 & 0.07 & -0.06 & 0.22 & 0.20 & -0.17 \\
\hline Weight & 0.08 & $0.43+$ & 0.24 & & $0.78 \times x \times 1$ & 0.34 & $-0.58 \times 7$ & -0.32 & 0.24 & 0.53 & -0.31 \\
\hline Fatmass & 0.06 & 0.38 & 0.20 & 0.78 & & $0.65 \times *$ & $-0.63 \times *$ & $-0.43+$ & 0.74 & 0.35 & -0.34 \\
\hline Tnsulin & -0.05 & $0.50 \%$ & 0.36 & 0.34 & $0.65 * x$ & & -0.32 & -0.22 & 0.69 & -0.12 & -0.18 \\
\hline 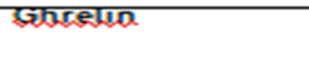 & -0.18 & -0.12 & 0.07 & $-0.58 * *$ & $-0.63^{* *}$ & -0.32 & & $0.73 \% * *$ & -0.22 & -0.43 & $0.55 *$ \\
\hline Amylin & -0.11 & -0.20 & -0.06 & -0.32 & -0.43 & -0.22 & $0.73^{* \ldots *}$ & & -0.23 & -0.31 & 0.33 \\
\hline Leptin & -0.03 & 0.31 & 0.22 & 0.24 & $0.74^{* * *}$ & $0.69 \times * 0$ & -0.22 & -0.23 & & -0.27 & -0.19 \\
\hline Osteo-pantio & -0.38 & -0.26 & 0.20 & 0.53 & 0.35 & -0.12 & -0.43 & -0.31 & -0.27 & & -0.20 \\
\hline Cortisol & 0.07 & -0.16 & -0.17 & -0.31 & -0.34 & -0.18 & $0.55^{*}$ & 0.33 & -0.19 & -0.20 & \\
\hline
\end{tabular}


Effects of endocrine and inflammatory changes on markers of bone turnover following roux-en-y gastric bypass surgery

Table 3B. Relationships among bone, endocrine, and inflammatory markers 12 months after RYGB.

$\mathrm{N}=20$. Pearson correlation coefficients are for absolute values in markers. Significant relationships are noted: $* \mathrm{p} \leq 0.05$, $* * \mathrm{p} \leq 0.01, * * * \mathrm{p} \leq 0.001, * * * * \mathrm{p} \leq 0.0001,+\mathrm{p} \leq 0.06$ (trend).

Using stepwise regression models, the variables that contributed to bone resorption before and after RYGB surgery included body weight at baseline, 1 and 3 months, cortisol at baseline and 6 months, HDL at 3 months, and adropin at 6 months (Table 4A). No variables contributed significantly to NTx at 12 months post RYGB. Over the post-operative period, the amount of variance in NTx explained by the regression models ranged from $29 \%$ at 1 month to almost $60 \%$ at 3 months.

As presented in Table 4B, the markers that significantly contributed to bone formation (BAP) before and after RYGB surgery included fasting plasma insulin at baseline and 12 months, ghrelin at baseline and 3 months, body weight at 1 and 3 months, visfatin and HDL at 3 months and HDL and cortisol at 6 months. The overall variance in BAP explained by these regression models ranged from $15 \%$ at 1 month to $63 \%$ at 3 months. 
Effects of endocrine and inflammatory changes on markers of bone turnover following roux-en-y gastric bypass surgery

The regression model of markers that contributed to the variance in BAP/NTx, as a measure of overall bone metabolism, before and 12 months after RYGB surgery is shown in Table 4C. At baseline, glucose (23\%) and FFA (12\%) explained $35 \%$ of the total variance in BAP/NTx. Twelve months after RYGB, $48 \%$ of the total variance in BAP/NTx was explained by glucose (22\%), insulin (17\%), and CRP (10\%). Neither body weight nor composition contributed to the explained variance in the BAP/NTx before or 12 months after RYGB.

Table 4A. Stepwise regression analysis of variables associated with NTx before and after RYGB.

\begin{tabular}{|c|c|c|c|c|c|}
\hline & Baseline & $\begin{array}{l} \\
\text { month }\end{array}$ & $\begin{array}{l}\mathbf{3} \\
\text { months }\end{array}$ & $\begin{array}{l}6 \\
\text { months }\end{array}$ & $\begin{array}{l}12 \\
\text { month } \\
\text { S } \\
\end{array}$ \\
\hline $\begin{array}{l}\text { Intercep } \\
\mathbf{t}\end{array}$ & $\begin{array}{l}- \\
50.8636 \\
6\end{array}$ & $\begin{array}{l}- \\
30.840 \\
4\end{array}$ & $\begin{array}{l}- \\
113.077 \\
6\end{array}$ & $\begin{array}{l}43.7291 \\
2\end{array}$ & ---- \\
\hline $\begin{array}{l}\text { Body } \\
\text { weight }\end{array}$ & $\begin{array}{l}0.68785 \\
(0.42)\end{array}$ & $\begin{array}{l}0.6272 \\
4 \\
(0.29)\end{array}$ & $\begin{array}{l}0.97388 \\
(0.47)\end{array}$ & ---- & ---- \\
\hline Cortisol & $\begin{array}{l}-0.37119 \\
(0.08)\end{array}$ & ---- & ---- & $\begin{array}{l}-0.43484 \\
(0.24)\end{array}$ & ---- \\
\hline HDL & ---- & ---- & $\begin{array}{l}1.86357 \\
(0.12)\end{array}$ & ---- & ---- \\
\hline Adropin & ---- & ---- & ---- & $\begin{array}{l}0.4291 \\
(0.12)\end{array}$ & \\
\hline $\begin{array}{l}\text { Model } \\
\mathbf{R}^{2}\end{array}$ & 0.50 & 0.29 & 0.59 & 0.35 & ---- \\
\hline
\end{tabular}

Table 4B. Stepwise regression analysis of variables associated with BAP before and after RYGB. 
Effects of endocrine and inflammatory changes on markers of bone turnover following roux-en-y gastric bypass surgery

\begin{tabular}{|c|c|c|c|c|c|}
\hline & $\begin{array}{l}\text { Baselin } \\
\text { e }\end{array}$ & $\begin{array}{l}\mathbf{1} \\
\text { month }\end{array}$ & $\begin{array}{l}3 \\
\text { months }\end{array}$ & $\begin{array}{l}6 \\
\text { months }\end{array}$ & $\begin{array}{l}12 \\
\text { months }\end{array}$ \\
\hline $\begin{array}{l}\text { Intercep } \\
\mathbf{t}\end{array}$ & $\begin{array}{l}56.5765 \\
1\end{array}$ & $\begin{array}{l}- \\
13.5440 \\
3\end{array}$ & $\begin{array}{l}64.6104 \\
0\end{array}$ & $\begin{array}{l}99.6385 \\
8\end{array}$ & $\begin{array}{l}13.6833 \\
8\end{array}$ \\
\hline Insulin & $\begin{array}{l}0.41168 \\
(0.22)\end{array}$ & ---- & ---- & ---- & $\begin{array}{l}0.47353 \\
(0.25)\end{array}$ \\
\hline Ghrelin & $\begin{array}{l}-0.1822 \\
(0.12)\end{array}$ & ---- & $\begin{array}{l}0.61167 \\
(0.10)\end{array}$ & ---- & ---- \\
\hline $\begin{array}{l}\text { Body } \\
\text { weight }\end{array}$ & ---- & $\begin{array}{l}0.38229 \\
(0.15)\end{array}$ & $\begin{array}{l}0.61257 \\
(0.09)\end{array}$ & ---- & ---- \\
\hline Visfatin & ---- & ---- & $\begin{array}{l}0.54663 \\
(0.25)\end{array}$ & ---- & ---- \\
\hline HDL & ---- & ---- & $\begin{array}{l}- \\
2.14951 \\
(0.19)\end{array}$ & $\begin{array}{l}- \\
1.07325 \\
(0.13)\end{array}$ & ---- \\
\hline Cortisol & ---- & ---- & ---- & $\begin{array}{l}- \\
0.28851 \\
(0.10)\end{array}$ & ---- \\
\hline $\begin{array}{l}\text { Model } \\
\mathbf{R}^{2}\end{array}$ & 0.34 & 0.15 & 0.63 & 0.23 & 0.25 \\
\hline
\end{tabular}

Table 4C. Regression analyses of variables associated with the BAP/NTx ratio before and after RYGB.

\begin{tabular}{lll}
\hline & Baseline & $\begin{array}{l}\text { 12 Months Post } \\
\text { RYGB }\end{array}$ \\
\hline Intercept & -0.33 & 4.08 \\
Glucose & $0.02(0.23)$ & $-0.04(0.22)$ \\
FFA & $1.97(0.12)$ & --- \\
Insulin & --- & $0.01(0.17)$ \\
CRP & --- & $-0.05(0.10)$ \\
Model R & 0.35 & 0.48 \\
\hline Values are regression coefficients (partial $\left.\mathbf{R}^{2}\right)$. \\
6. 0 Discussion
\end{tabular}

There were two unique aspects to this study. First was the use of a BAP/NTx ratio as a biomarker of long-term bone metabolism, thereby allowing for the evaluation of which marker is more important to the overall change in bone health

Marta.vanloan@ars.usda.gov

Copyright 2015 KEI Journals. All Rights Reserved

21 


\section{Medical Research Archives}

Effects of endocrine and inflammatory changes on markers of bone turnover following roux-en-y gastric bypass surgery

during a period of transient bone remodeling. Second was the use of stepwise regression model of interactions among the skeletal, endocrine, and immune systems during a long term period of persistent weight loss. We previously reported relationships among pancreatic and adipocyte hormones glucose, insulin, fatty acids and markers of inflammation longitudinally for one year following RYGB. [Swarbrick et al. 2008]. Here we examined the relationships between these parameters and markers of bone metabolism.

The results of this study reveal that the interactions among the skeletal, endocrine, and immune systems fluctuate dramatically over a one year period of consistent and marked weight loss following RYGB, making it difficult to understand the complex relationships of these systems. This is evident in the stepwise regression models with different variables making different contributions to the models over the year. Therefore, we proposed the use of the BAP/NTx ratio as a more stable index of bone metabolism during periods of consistent and persistent weight loss.

Our finding of a significant increase in bone resorption in the year after RYGB is consistent with previous reports [Grethen et al. 2012, Bruno et al. 2010, El Kadre et al. 2004, Casagrande et al. 2012, Coates et al. 2004, Stein et al. 2013, Biagioni et al. 2013, Sinha et al. 2011, Mahdy et al. 2008]. Also, as we 
Effects of endocrine and inflammatory changes on markers of bone turnover following roux-en-y gastric bypass surgery

previously reported [Swarbrick et al. 2006, Swarbrick et al. 2008], and in subsequent accordance with other published reports, are significant changes of leptin [Hage and Fuleihan 2014, Brzozowska et al. 2013, Grethan et al. 2012, Beckman et al. 2011, Beckman et al. 2010, Bruno et al. 2010, Riedl et al. 2008, Coates et al. 2004], insulin [Raffaeli et al. 2014], and adiopnectin [Hage and Fuleihan 2014, Viegas et al. 2010, Carrasco et al. 2009, Gomez et al. 2009, Holdstock et al. 2003] observed in the post-operative period. Reduced inflammation is also consistent with prior studies [Swarbrick et al. 2008, Sinha et al. 2013, Thomsen et al. 2013, Reid et al. 2008].
Elevated levels of insulin have been shown to reduce sex hormone binding globulin and stimulate ovarian estrogen production, thus increasing free sex hormones, which promote osteoblast activity and decrease osteoclast activity [Reid 2010, Cornish et al. 2009]. Insulin works in conjunction with other endocrine pancreatic products amylin and preptin, which also have been reported to have beneficial effects on bone health [Reid 2010, Cornish et al. 2009]. A feed-forward boneendocrine loop has been proposed in which insulin receptor signaling on osteoblasts stimulates osteocalcin production, and un carboxylated osteocalcin acts back on the pancreas to stimulate insulin secretion [Fulzele and Clemens 2012, 


\section{Medical Research Archives}

Effects of endocrine and inflammatory changes on markers of bone turnover following roux-en-y gastric bypass surgery

Karsenty and Ferron 2012]. Hepatic insulin sensitivity is thought to improve immediately after RYGB due to energy restriction and quick endocrine changes, and later weight loss leads to improvement in peripheral insulin sensitivity [Dirksen et al. 2012, Campos et al. 2010]. A small study reported that acute changes of plasma insulin concentrations over the normal physiological range do not affect biomarkers of bone turnover in humans, but these findings do not rule out the potential impact of the marked long-term changes of plasma insulin following RYGB [Swarbrick,et al. 2008, Basu et al. 2011]. Therefore, a sustained lowering of circulating insulin levels after RYGB could prove detrimental to bone health [Hage and
Fuleihan 2014]. A recent study of postmenopausal Hispanic women seven years after RYGB suggested an adverse correlation between percent change in C-teleopeptide of type 1 collagen (CTx) from baseline and peak insulin levels after standard meal [Valderas et al. 2014]. However, the role of postprandial changes of plasma insulin on indices of bone turnover after RYGB remains largely unexplored and requires further investigation.

Osteopontin, a glycoprotein secreted by both osteoclasts and macrophages, was correlated with bone turnover markers Cterminal teleopeptide of type I collagen (ICTP) and osteocalcin in a recent study [Lancha et al. 2014]. However, while

Marta.vanloan@ars.usda.gov

Copyright 2015 KEI Journals. All Rights Reserved

24 
Effects of endocrine and inflammatory changes on markers of bone turnover following roux-en-y gastric bypass surgery

circulating osteopontin increased significantly following

RYGB, the present data do not support associations between osteopontin and bone turnover markers BAP and NTx. Likewise, we found no significant correlations between osteopontin and inflammatory markers, or any other variable, before and after RYGB. These findings are similar to a previous report [Schaller et al. 2009].

White adipose tissue can become infiltrated by macrophages, which are then activated and increase the expression of proinflammatory molecules, leading to systemic inflammation [Thomsen et al. 2013]. Pro-inflammatory cytokines such as tumor necrosis factor alpha (TNF) and interleukin-6 (IL-6) are related to increased bone resorption [Gomez-Ambrosi et al. 2008], so a beneficial effect on bone is expected with the reduction of inflammatory markers after RYGB. Findings of the present study support this hypothesis. Ten percent of the variance in the BAP/NTx ratio at twelve months post surgery was explained by CRP. Likewise, in a study of 40 bariatric surgery patients ( $\mathrm{n}=30 \mathrm{RYGB}$ ), the pro-inflammatory cytokine osteopontin was correlated with CTx and osteocalcin 12 months after surgery [Riedl et al. 2008]. Conversely, soluble TNF receptors 1 and 2 were not significantly associated with BMD changes one year after gastric bypass surgery in a cohort study [Gomez et al. 2009]. Clearly, additional research is 
Effects of endocrine and inflammatory changes on markers of bone turnover following roux-en-y gastric bypass surgery

needed to determine the causal relationships between RYGBinduced changes in skeletal, endocrine, and immune systems.

As a secondary analysis of a longitudinal investigation of endocrine effects of RYGB, the present study has several limitations. Parathyroid hormone and 25-hydroxyvitamin D were not included as part of the original study, and we were unable to measure these hormones in the plasma that remained after other analyzes had been completed. Dietary intake and supplement use were not recorded, and, therefore, the effects of these variables on bone outcomes could not be examined. At the time of data collection, available DXA equipment was unable to assess bone density in severely obese subjects, so
BMD data were unavailable for this study. All measurements were performed on plasma or serum collected in the fasted state, so postprandial changes in bone markers after RYGB were not explored. The one-year duration of this study may have been insufficient to detect potential plateaus of bone turnover markers that have been reported in longer term studies [Granado-Lorencio et al. 2010]. Additionally, the sample size was relatively small, and there was not a control group of unoperated subjects for comparison.

$\underline{\text { Conclusions }}$ 


\section{Medical Research Archives}

Effects of endocrine and inflammatory changes on markers of bone turnover following roux-en-y gastric bypass surgery

The present study was unique in two aspects 1) the use the BAP/NTx ratio as a means of evaluating long term changes in bone metabolism during a period of continuous weight loss, thus avoiding misinterpretation due to bone transient remodeling and 2) stepwise regression models to demonstrate the continually changing landscape among the skeletal, endocrine and immune systems following RYGB with persistent weight loss over a one year period. The beneficial improvements in insulin resistance, through decreased insulin exposure, may promote the uncoupling of osteoblast and osteoclast activity, and this uncoupling may be responsible for the increased resorption. Reduced inflammation may also have influenced the bone markers, but not sufficiently to counteract the effects of insulin and glucose. In this study, hormonal and inflammatory changes appear to modify bone metabolism to a greater degree than changes of body weight or composition, suggesting a more limited role for mechanical unloading. Future studies with larger sample sizes, longer durations, and with nutritional intake data, will help to further define the complex mechanisms of how bone metabolism appears to be negatively affected after RYGB in the face of improved endocrine and immune system profiles.

\section{$\underline{\text { Acknowledgements }}$}


Effects of endocrine and inflammatory changes on markers of bone turnover following roux-en-y gastric bypass surgery

We thank the following individuals for their contributions to

this project: IT Austrheim-Smith, A Butler, ER Gertz, J

Graham, E Nuñez.Funding: UC Davis Health Care Systems

grant; UC Davis CTSC (UL1 RR024146); National Center for

Research Resources; USDA/ARS/WHNRC.USDA is an equal

opportunity provider and employer.

Marta.vanloan@ars.usda.gov

Copyright 2015 KEI Journals. All Rights Reserved 
Effects of endocrine and inflammatory changes on markers of bone turnover following roux-en-y gastric bypass surgery

\section{$\underline{\text { References }}$}

Barbour KE, Zmuda JM, Boudreau R, Stotmeyer ES, Horwitz MJ, Evans RW et al. 2012. The effects of adiponectin and leptin on change in bone mineral density. Osteoporos Int; 23:1699-1710.

Basu A, Devaraj S, Jialal I. 2006. Dietary factors that promote or retard inflammation. Arterioscler Thromb Vasc Biol; 26:995-1001.

Basu R, Peterson J, Rizza R, Khosla S. 2011. Effects of physiological variations in circulating insulin levels on bone turnover in humans. J Clin Endocrinol Metab; 96(5):14501455.

Beckman LM, Beckman TR, Earthman CP. 2010. Changes in gastrointestinal hormones and leptin after Roux-en-Y gastric bypass procedure: a review. J Am Diet Assoc; 110:571-584.

Beckman LM, Beckman TR, Sibley SD, Thomas W, Ikramuddin S, Kellogg TA et al. 2011. Changes in gastrointestinal hormones and leptin after Roux-en-Y gastric bypass surgery. J Parenter Enteral Nutr; 35:169-180.

Biagioni MF, Mendes AL, Nogueira CR, Pavia SA, Leite CU, Mazeto GM. 2014. Weight-reducing gastroplasty with Rouxen-Y gastric bypass: impact on vitamin $D$ status and bone remodeling markers. Metab Syndr Related Disord; 12(1):1115.

Blum M, Harris SS, Must A, Naumova EN, Phillips SM, Rand WM et al. 2003. Leptin, body composition and bone mineral density in pre-menopausal women. Calcif Tissue Int; 73:27-32.

Bruno C, Fulford AD, Potts JR, McClintock R, Jones R, Cacucci BM et al. 2010. Serum markers of bone turnover are increased at six and eighteen months after Roux-en-Y bariatric surgery: correlation with the reduction in leptin. J Clin Endocrinol Metab; 95:159-166.

Brzozowska MM, Sainsbury A, Eisman JA, Baldock PA, Center JR. 2013. Bariatric surgery, bone loss, obesity and possible mechanisms. Obes Rev; 14:52-67. 
Effects of endocrine and inflammatory changes on markers of bone turnover following roux-en-y gastric bypass surgery

Campos GM, Rabl C, Peeva S, Ciovica R, Rao M, Schwarz JM et al. 2010. Improvement in peripheral glucose uptake after gastric bypass surgery is observed only after substantial weight loss has occurred and correlates with the magnitude of weight loss. J Gastrointest Surg; 14(1):15-23.

Carrasco F, Ruz M, Rojas P, Csendes A, Rebolledo A, Codeceo J et al. 2009. Changes in bone mineral density, body composition and adiponectin levels in morbidly obese patients after bariatric surgery. Obes Surg; 19:41-46.

Casagrande DS, Repetto G, Mottin CC, Shah J, Pietrobon R, Worni M, Schaan BD. 2012. Changes in bone mineral density in women following one-year gastric bypass surgery. Obes Surg; 22:1287-1292.

Coates PS, Fernstrom JD, Fernstrom MH, Schauer PR, Greenspan SL. 2004. Gastric bypass surgery for morbid obesity leads to an increase in bone turnover and a decrease in bone mass. J Clin Endocrinol Metab; 89:1061-1065.
Considine RV, Sinha MK, Heiman ML, Kriauciunas A, Stephens TW, Nyce MR, Ohannesian JP, Marco CC, McKee LJ, Bauer TL, Caro JF. 1996. Serum immunoreactive-leptin concentrations in normal-weight and obese humans. N Engl J Med.; 334:292-295.

Cornish J, Callon KE, Bara U, Lin C, Naot D, Hill BL et al. 2002. Leptin directly regulates bone cell function in vitro and reduces bone fragility in vivo. J Endocrinol; 175:405-415.

Cornish J, Costa JL and Naot D. The bone-fat mass relationship: laboratory studies. IBMS BoneKEy 2009; 6(9):311-322.

Dirksen C, Jorgensen NB, Bojesen-Moller KN, Jacobsen SH, Hansen DL, Worm D et al. 2012. Mechanisms of improved glycemic control under Roux-en-Y gastric bypass. Diabetologia; 55:1890-1901.

Ducy P, Amling M, Takeda S, Priemel M, Schilling AF, Beil FT et al. 2000. Leptin inhibits bone formation through a 
Effects of endocrine and inflammatory changes on markers of bone turnover following roux-en-y gastric bypass surgery

hypothalamic relay: a central control of bone mass. Cell; 100:197-207.

El-Kadre LJ, Rocha PR, de Almeida Tinoco AC, Tinoco RC. 2004. Calcium metabolism in pre- and post-menopausal morbidly obese women at baseline and after laproscopic Rouxen-Y gastric bypass. Obes Surg; 14(8):1062-1066.

Folli F, Sabowitz BN, Schwesinger W, Fanti P, GuardadoMendoza R, Muscogiuri G. 2012. Bariatric surgery and bone disease: from clinical perspective to molecular insights. Int $\mathbf{J}$ Obes; 36:1373-1379.

Frederich RC, Hamann A, Anderson S, Lollmann B, Lowell BB, Flier JS. 1995. Leptin levels reflect body lipid content in mice: evidence for diet-induced resistance to leptin action. Nat Med.; 1:1311-1314.

Fulzele K and Clemens TL. 2012. Novel functions for insulin in bone. Bone; 50:452-456.

Gómez JM, Vilarrasa N, Masdevall C, Pujol J, Solano E, Soler $\mathrm{J}$ et al. 2009. Regulation of bone mineral density in morbidly obese women: a cross-sectional study in two cohorts before and after bypass surgery. Obes Surg; 19:345-350.

Gómez-Ambrosi J, Rodriguez A, Catalán V, Frühbeck G. 2008. The bone-adipose axis in obesity and weight loss. Obes Surg; 18:1134-1143.

Granado-Lorencio F, Simal-Antón A, Salazar-Mosteiro J, Herrero-Barbudo C, Donoso-Navarro E, Blanco-Navarro I et al. 2010. Time-course changes in bone turnover markers and fat soluble vitamins after obesity surgery. Obes Surg; 20:15241529.

Grethen E, Hill KM, Jones R, Cacucci BM, Gupta CE, Acton A et al. 2012. Serum leptin, parathyroid hormone, 1,25 Dihydroxyvitamin D, fibroblast growth factor 23, bone alkaline phosphatase and sclerostin relationships in obesity. J Clin Endocrinol Metab; 97:1655-1662.

Hage MP and Fuleihan GE. 2014. Bone and mineral metabolism in patients undergoing Roux-en-Y gastric bypass. Osteoporos Int; 25:423-439. 
Effects of endocrine and inflammatory changes on markers of bone turnover following roux-en-y gastric bypass surgery

Havel PJ. 2004. Update on adipocyte hormones: regulation of energy balance and carbohydrate/lipid metabolism. Diabetes;53 (Supp 1):S143-S151.

Holdstock C, Engström BE, Öhrvall M, Lind L, Sundbom M, Karlsson FA. 2003. Ghrelin and adipose tissue regulatory peptides: effect of gastric bypass surgery in obese humans. $\mathbf{J}$ Clin Endocrinol Metab; 88:3177-3183.

Jürimäe J, Kums T, Jürimäe T. 2009. Adipocytokine and ghrelin levels in relation to bone mineral density in physically active older women: longitudinal associations. Eur J Endocrinol; 160:381-385.

Karsenty G and Ferron M. The contribution of bone to wholeorganism physiology. 2012. Nature; 481:314-320.

Koroglu BK, Kiris F, Ersoy IH, Sutcu R, Yildiz M, Aksu O et al. 2011. Relationship of leptin, adiponectin and insulin resistance to bone mineral density in type 2 diabetic postmenopausal women. Pol J Endocrinol; 62(5):429-435.
Lancha A, Moncada R, Valentí V, Rodríguez A, Catalán V, Becerril $S$ et al. 2014. Comparative effects of gastric bypass and sleeve gastrectomy on plasma osteopontin concentrations in humans. Surg Endosc 28:2412-2420.

Lee Y, Kim M, Choi K, Kim J, Bae W, Kim S et al. 2011. Relationship between inflammation biomarkers, antioxidant vitamins, and bone mineral density in patients with metabolic syndrome. Nutr Res Pract; 5(2):150-156.

Mahdy T, Atia S, Farid M, Adulatif A. 2008. Effect of Rouxen-Y gastric bypass on bone metabolism in patients with morbid obesity: Mansoura experiences. Obes Surg; 18:15261531.

McCormick RK. 2007. Osteoporosis: integrating biomarkers and other diagnostic correlates into the management of bone fragility. Altern Med Rev; 12(2):113-145.

Mechanick JI, Youdim A, Jones DB, Garvey WT, Hurley DL, McMahon MM et al. 2013. Clinical practice guidelines for the perioperative nutritional, metabolic, and nonsurgical support of 
Effects of endocrine and inflammatory changes on markers of bone turnover following roux-en-y gastric bypass surgery

the bariatric surgery patient- 2013 update: cosponsored by the American Association of Clinical Endocrinologists, the Obesity Society, and the American Society for Metabolic and Bariatric Surgery. Obesity; 21:S1-S27.

akamura KM, Haglind EGC, Clowes JA, Achenbach SJ, Atkinson EJ, Melton III LJ, Kennel KA. 2014. Fracture risk following bariatric surgery: a population-based study. Osteoporos Int; 25:151-158.

Raffaelli M, Guidone C. Callari C, Iaconelli A, Bellatone R, Mingrone G. 2014. Effect of gastric bypass versus diet on cardiovascular risk factors. Ann Surg; 259:694-699.

Reid IR. 2010. Fat and bone. Arch Biochem Biophys; 503:2027.

Riedl M, Vila G, Maier C, Handisurya A, Shakeri-Manesch S, Prager $G$ et al. 2008. Plasma osteopontin increases after bariatric surgery and correlates with markers of bone turnover but not insulin resistance. J Clin Endocrinol Metab; 93:23072312 .
Schaller G, Aso Y, Schernthaner GH, Kopp HP, Inukai T, Kriwanek $S$ et al. 2009. Increase of osteopontin plasma concentrations after bariatric surgery independent from inflammation and insulin resistance. Obes Surg; 19:351-356.

Schweitzer DH. 2007. Mineral metabolism and bone disease after bariatric surgery and ways to optimize bone health. Obes Surg; 17:1510-1516.

Scibora LM, Ikramuddin S, Buchwald H, Petit MA. 2012. Examining the link between bariatric surgery, bone loss, and osteoporosis: a review of bone density studies. Obes Surg; 22:654-667.

Sinha N, Shieh A, Stein EM, Strain G, Schulman A, Pomp A et al. 2011. Increased PTH and 1,25(OH)(2)D levels associated with increased markers of bone turnover following bariatric surgery. Obesity (Silver Spring); 19(12):2388-2393.

Stein EM, Carrelli A, Young P, Bucovsky M, Zhang C, Schrope B et al. 2013. Bariatric surgery results in cortical bone loss. J Clin Endocrionl Metab; 98:541-549. 
Effects of endocrine and inflammatory changes on markers of bone turnover following roux-en-y gastric bypass surgery

Stein EM and Silverberg SJ. 2014. Bone loss after bariatric surgery: causes, consequences, and management. Lancet Diabetes Endocrionol; 2:165-174.

Swarbrick MM, Austrheim-Smith IT, Stanhope KL, Van Loan MD, Ali MR, Wolf BM et al. 2006. Circulating concentrations of high-molecular-weight adiponectin are increased following Roux-en-Y gastric bypass surgery. Diabetologia; 49:25522558.

Swarbrick MM, Stanhope KL, Austrheim-Smith IT, Van Loan MD, Ali MR, Wolfe BM, et al. 2008. Longitudinal changes in pancreatic and adipocyte hormones following Roux-en-Y gastric bypass surgery. Diabetologia;51:1901-1911.

Thomsen SB, Rathcke CN, Jorgensen NB, Madsbad S, Vestergaard H. Effects of Roux-en-Y gastric bypass on fasting and post-prandial levels of the inflammatory markers YKL-40 and MCP-1 in patients with type 2 diabetes and glucose tolerant subjects. J Obes 2013; Article ID 361781, 10 pages.
Turner RT, Kalra SP, Wong CP, Philbrick KA, Lindenmaier LB, Boghossian $\mathrm{S}$ et al. Peripheral leptin regulates bone formation. J Bone Miner Res 2013; 28(1):22-34.

Valderas JP, Padilla O, Solari S, Escalona M, González G. Feeding and bone turnover in gastric bypass. J Clin Endocrinol Metab 2014; 99:491-497.

Viégas M, Simoes de Vasconcelos R, Neves AP, Diniz ET, Bandeira F. Bariatric surgery and bone metabolism: a systematic review. Arq Bras Endocrinol Metab 2010; 54(2):158-163.

Vilarrasa N, San José P, Garcia I, Gómez-Vaquero C, Miras PM, Ruiz de Gordejuela AG et al. Evaluation of bone mineral density loss in morbidly obese women after gastric bypass: three year follow up. Obes Surg 2011; 21:465-472.

Williams SE. Metabolic bone disease in the bariatric surgery patient. J Obes 2011. Article ID 634614, 9 pages.

Yamauchi M, Sugimoto T, Yamaguchi T, Nakaoka D, Kanzawa M, Yano $\mathrm{S}$ et al. Plasma leptin con 
Effects of endocrine and inflammatory changes on markers of bone turnover following roux-en-y gastric bypass surgery

centrations are associated with bone mineral density and the presence of vertebral fractures in postmenopausal women. Clin

Endocrinol 2001; 55:341-347.
Yu EW. Bone metabolism after bariatric surgery. J Bone Miner Res 2014; 29(7):1507-1518 